\title{
Práticas de prevenção do HIVIAids e modos de subjetivação
}

\section{| ${ }^{1}$ Clara Virgínia de Queiroz Pinheiro, ${ }^{2}$ Nathassia Matias de Medeiros |}

Resumo: Considerando que as políticas públicas de controle e prevenção do HIV/Aids abordam a atividade sexual dos indivíduos a fim de suprimir os comportamentos de risco, infere-se o caráter normativo dessas intervençôes, uma vez que questionam as condutas segundo os critérios de saúde, impondo-os como medida da experiência sexual. Pressupõe-se, então, que as estratégias de normatização dos comportamentos sexuais conforme os códigos preventivos envolvem um processo de subjetivação. Tal proposição se baseia nas concepções foucaultianas acerca da experiência moral, que ele distingue em três aspectos: a norma, as ações e a relação de si consigo. $\mathrm{O}$ comportamento sexual se tornou objeto das práticas de prevenção do HIV/Aids baseado em um campo de conhecimento médico que problematiza a saúde a partir da relação do organismo com o meio, englobando, assim, os aspectos biopsicossociais. Portanto, é pelo caráter de vulnerabilidade relacionado ao comportamento sexual que os indivíduos são tomados como alvo das políticas de saúde. Trata-se, então, de investigar os fatores de risco relacionados à ocorrência da síndrome na população. Dessa forma, é em referência ao estatuto de vulnerabilidade condicionado ao exercício da sexualidade que o sujeito inscreve em sua relação consigo mesmo a norma de saúde, impondo-se o cumprimento da conduta sexual saudável. Por isso, investigase, neste trabalho, a prevalência das normas médicas nas atitudes sexuais dos sujeitos, com base nas relações intrínsecas entre a forma como o indivíduo é objetivado pelos saberes médicos e o processo pelo qual o sujeito posiciona suas ações em observância aos códigos de saúde.

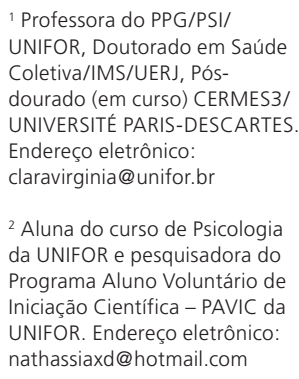

1 Professora do PPG/PSI/ UNIFOR, Doutorado em Saúde Coletiva/IMS/UERJ, Pósdourado (em curso) CERMES3/ UNIVERSITÉ PARIS-DESCARTES Endereço eletrônico: claravirginia@unifor.br

2 Aluna do curso de Psicologia da UNIFOR e pesquisadora do Programa Aluno Voluntário de Iniciação Científica - PAVIC da UNIFOR. Endereço eletrônico: nathassiaxd@hotmail.com 


\section{Construção do problema}

Há trinta anos, a síndrome da imunodeficiência adquirida (Aids) surge como um grande problema de saúde coletiva. De acordo com o Boletim Epidemiológico - Aids/DST de 2010, atualizado em junho de 2011 pelo Ministério da Saúde, atualmente, no Brasil, existem 608.230 casos de Aids notificados no período de 1980 a junho de 2011. O total de óbitos declarados no Sistema de Informações sobre Mortalidade (SIM) tendo como causa básica a Aids, foi de 241.469 nesse mesmo período. A síndrome de imunodeficiência adquirida torna-se ameaça à população, chegando mesmo a ser considerada perigo de extensão global. Dessa forma, em torno do HIV/Aids foram mobilizadas estratégias, práticas e saberes em vários níveis: social, político, médico, econômico, etc., com vistas à assistência e à prevenção. (ALMEIDA; LABRONICI, 2007).

No campo da assistência, as intervenções produziram mudanças efetivas na vida dos indivíduos infectados. A introdução do tratamento antirretroviral triplo de alta potência (TARV) acarretou, conforme Alencar, Nemes e Velloso (2008), a diminuição das taxas de mortalidade, o que levou à classificação da Aids como doença crônica. Na década de 1980, a Aids era classificada como uma doença aguda, ou seja, possuía manifestações rápidas após o estabelecimento do diagnóstico, levando rapidamente à morte.

Em 1996, a terapia antirretroviral começou a ser distribuída gratuitamente pelo Brasil, um dos primeiros países a oferecer a medicação às pessoas vivendo com HIV e Aids, garantida através da Lei n. 9.313/96. Com a introdução da TARV, em conjunto com outros fatores, dentre eles as descobertas sobre a natureza da infecção por HIV e as técnicas de monitoramento do avanço da doença, como os exames de CD4 e de carga viral, tornou-se possível para os indivíduos viver por mais anos com HIV e Aids.

Paralelamente à intervenção clínica, são sistematicamente realizados estudos epidemiológicos que abordam o problema na população, visando conhecer os índices de disseminação do vírus, fatores de risco e probabilidades de ocorrência em longo prazo. Tais conhecimentos fundamentam as políticas públicas de controle e prevenção do HIV/Aids. Com efeito, a identificação de certos comportamentos de risco relativos à transmissão do HIV, tais como sexo sem camisinha e uso compartilhado de seringas, levou à definição de estratégias pedagógicas, sociais, médicas e psicológicas, com a finalidade de influenciar mudanças de atitudes da 
população a respeito da vida sexual, conduzindo à redução da vulnerabilidade.

Podemos citar algumas açóes preventivas, tais como, o Plano de Enfrentamento da Epidemia de Aids e das DST entre gays, HSH e travestis (2008); Projeto Saúde e Prevenção nas Escolas (SPE) (2003); Plano Integrado de Enfrentamento da Feminização da Epidemia de Aids e outras DST (2007).

Devemos salientar que essas intervenções não se definem pelo caráter repressivo, desautorizando a legitimidade de determinados comportamentos, interditando ou patologizando-os. Não se trata de condenar a prática sexual nem o uso de drogas; o que se prescreve é que as normas de saúde prevaleçam sobre as experiências de vida, não importam quais. Daí, por exemplo, a campanha publicitária veiculada no carnaval de 2010: "Camisinha. Com amor, paixão ou só sexo mesmo. Use sempre". Tampouco devemos pensar que as estratégias preventivas focalizam seus recursos no poder transformador da informação, pois, como pondera Fernandes (1994, p.171): “a questão da mudança de hábitos, particularmente, nos campos diretamente implicados da transmissão do HIV, está bem longe de ser simples e transcende, sem dúvida, o aspecto estritamente informativo".

Assim, pressupomos o caráter normativo desses discursos e práticas preventivas, uma vez que consistem em situar as ações face aos códigos de saúde e doença, objetivando instaurar, fomentar e fortalecer uma inquietação nos indivíduos a respeito dos cuidados com a saúde na vida quotidiana, influenciando, consequentemente, mudanças de atitudes, expectativas, prioridades, etc. Com efeito, como nos esclarece Legrand (2007), um enunciado é normativo pela função de exigência que exerce sobre as ações, segundo determinados critérios, em relação aos quais o indivíduo deve pôr-se ou ser posto em questão. As campanhas publicitárias, as pesquisas de comportamentos e atitudes e os programas de saúde e prevenção nas escolas, entre outros, explicitam o valor de comportamentos que agregam cuidados com a saúde relativos à prevenção do HIV/Aids.

Esses discursos e práticas problematizam o sentido de certas experiências, como as românticas, sob o critério da saúde e da prevenção do HIV. Encontramos, então, na história em quadrinhos "Todas as Claudinhas do Mundo", ${ }^{2}$ publicada pelo Ministério da Saúde, dentro do programa de prevenção nas escolas, uma referência ao romance Romeu e Julieta, de William Shakespeare, a respeito do qual se discute o amor trágico, que culmina com morte dos amantes. Tal citação conduz a uma reflexão sobre o amor como um elo entre paixão e razão, pois 
amar, conclui Claudinha (protagonista da história), é cuidar (da vida) um do outro. Podemos ressaltar aí um procedimento de subordinar, a propósito das vivências sexuais e amorosas, os códigos do amor romântico (amor intenso) aos padrões de uma vida saudável. Em outras palavras, vemos aí estratégias que procuram inscrever na atividade sexual, em qualquer situação - sexo casual ou sexo com amor - , as medidas preventivas.

Mas, então, é preciso se perguntar: como esse imperativo da prevenção em toda e qualquer relação sexual se concretiza nas práticas dos indivíduos? Como afirmamos acima, não se trata de uma exigência que se impõe como uma lei, cujo não cumprimento acarreta penalidades, como no caso, por exemplo, da obrigatoriedade do uso do cinto de segurança para passageiros e motoristas de automóveis. Ora, supomos que a visada normativa da conduta sexual, segundo os preceitos da qualidade de vida, das políticas públicas de controle do HIV/ Aids, envolve, além das prescrições médicas, uma forma de implicação do sujeito como responsável, pela qual o indivíduo se impõe a regulação da conduta sexual conforme os ditames da prevenção.

Essa proposição acerca dos modos de subjetivação implicados nas políticas públicas se baseia na concepção foucaultiana de subjetividade como forma de relação a si, cuja figura se define em relação ao campo dos sistemas de valores (morais, sociais e, claro, médicos, entre outros). Com efeito, a relação a si é, segundo Foucault, um dispositivo pelo qual os valores se inscrevem na conduta dos indivíduos, além das prescrições e práticas de formação. Assim, Foucault $(1984 ; 1994)$ esclarece que uma conduta moral não só diz respeito às regras, "mas ela implica uma certa relação a si; essa relação não é simplesmente 'consciência de si', mas constituição de si enquanto 'sujeito moral'”. Eis, portanto, a concepção foucaultiana de subjetividade, como relação a si, implicada na forma como os indivíduos se conduzem em observância a determinados princípios.

Daí consideramos, inspirados nas formulações foucaultianas, que o cuidado preventivo com a conduta sexual diz respeito às prescrições (tais como usar camisinha), às praticas (educativas/informativas, por exemplo) e também à relação a si, que se refere à valorização médica/social do sujeito responsável pela própria saúde, vivendo com qualidade de vida. Assim, propomo-nos a estudar as políticas públicas de combate ao HIV/Aids, objetivando explicitar o modo de subjetivação implicado na conduta sexual regulada pela prevenção. Portanto, 
abordamos os discursos e as práticas de políticas públicas de saúde com o objetivo

de examinar a especificidade do processo subjetivo fundado num campo de relações sociais em que dominam dispositivos de normalização das condutas segundo os critérios de prevenção do HIV/Aids.

Com esse propósito, abstemo-nos de emitir qualquer juízo acerca da qualidade das experiências subjetivas inerentes a esse contexto normativo; entretanto, não nos eximimos de admitir, em conformidade com as ideias foucaultianas, que as relaçóes de poder podem produzir soluçóes a respeito de determinados problemas, mas também encerram perigos aos modos de existência humana. É o caso da depressão, por exemplo, considerada por Ehrenberg (2000) como uma forma de sofrimento psíquico relacionado ao imperativo para que o indivíduo previna-se em suas relaçôes sexuais. Os cuidados preventivos são considerados como próprios de um sujeito responsável, que normativa suas ações, visando à eliminação da vulnerabilidade e à melhoria de suas condições de autonomia. Eis, então, a depressão como uma forma de sofrimento psíquico que, por um lado, remete ao sistema de normas, pelo o qual o sujeito é valorizado pelo seu estado de saúde, devido à eliminação de seus comportamentos de risco, e, por outro lado, diz respeito ao modo de sujeição ao modelo de sujeito responsável pela qualidade de vida. Ora, podemos dizer, de acordo com a tese de Ehrenberg, que a depressão é inerente a um campo de valores, a propósito do qual o indivíduo é instigado a regular seus comportamentos de risco, devido a sua condição de sujeito responsável pela sua condição de autonomia.

Ademais, julgamos que a relevância deste estudo consiste em explorar uma perspectiva que postula a relação de implicação do sujeito nos dispositivos de prevenção e de normalização das condutas, de acordo com os códigos de saúde. Daí, podemos considerar que as intervenções a respeito da epidemia são um espaço de experiência, a propósito do qual se pode assinalar os efeitos positivos na qualidade de vida dos indivíduos, como assistência às pessoas que vivem com HIV/Aids, estratégias para fazer valer a legitimidade das minorias sexuais, etc. Por outro lado, é possível também reconhecer os reversos desse espaço de experiência, pois supomos que os problemas oriundos das tensóes e conflitos inerentes ao enfrentamento da ameaça de infecção, tais como preconceitos, discriminações, estigmas, baixa autoestima, exclusão, medo, depressão, violência, entre tantos outros, são a contrapartida de uma engrenagem que faz funcionar o cumprimento 
da norma de saúde como medida do sujeito responsável. Em outras palavras, entendemos os dissabores sociais e pessoais relacionados à síndrome do HIV/ Aids como resultantes do caráter normativo dos saberes e práticas preventivas, que situam o sujeito responsável como agente de sua qualidade de vida.

\section{Pressupostos teórico-metodológicos}

Dessa maneira, no presente estudo, partimos do pressuposto de que os discursos e as estratégias de prevenção do HIV/Aids possuem caráter normativo, na medida em que atuam sobre as ações dos indivíduos. Assim, abordamos esse domínio de saberes e práticas tendo em vista um estudo sobre os processos pelos quais os indivíduos assumem as prescrições médicas de cuidados da saúde, de modo a se posicionarem como sujeitos de suas condiçōes de vida, quer dizer, tal como explicita Legrand (2007, p.155), de se formarem como "matriz virtual das açôes". Em outros termos, situamos a questão de saber sobre a maneira pela qual os sujeitos concretizam em si mesmos os preceitos de saúde, isto é, conduzem suas ações em conformidade com as normas características da conjuntura médicopolítica de abordagem preventiva do HIV/Aids.

Trata-se, portanto, de um estudo sobre as relações entre formas de subjetivação e intervençôes preventivas sobre HIV/Aids. A pertinência de tal questionamento se fundamenta na perspectiva foucaultiana, que postula, de um lado, a dimensão política e ética das práticas de saúde, ressaltando sua função normativa, quer dizer, seu caráter de exigência acerca dos cuidados com a vida; de outro lado, postula-se a instituição de modos de subjetivação no interior de um campo científico e técnico, considerando que há uma sujeição do indivíduo aos ideais preventivos da ótica médica, que engendra uma forma de relação a si, pela qual o sujeito se responsabiliza pelas suas próprias condiçōes de saúde. Assim, como explicita Legrand (2007, p.235):

o assujeitamento supõe ao mesmo tempo uma produção de verdade, uma codificação do indivíduo em relação a essa produção, mas, também, uma assunção dessa verdade pelo indivíduo, uma participação ativa, uma autentificação subjetiva disso que ela marca no real.

Com efeito, não abordamos a experiência subjetiva no contexto da saúde pública, partindo da ideia de um sujeito previamente constituído, que, em situação de vulnerabilidade, é confrontado pelos conhecimentos científicos 
sobre as manifestações dos fatos biológicos, os quais detêm, em si mesmos, em sua realidade, o poder de produzir reações e defesas. Supomos, na esteira das pesquisas foucaultianas, que a submissão do indivíduo às prescrições de cuidados não se deve, fundamentalmente, a um processo de esclarecimentos acerca das razóes científicas sobre os fatos patológicos, suas terapêuticas e formas de prevenção; tampouco à interiorização da ordem médica, através da qual o sujeito assume a função de agente de saúde. Trata-se, então, de examinar o processo de subjetivação estreitamente relacionado à maneira pela qual o indivíduo é tomado como objeto dos discursos e das práticas médicas, quer dizer, definido e manipulado segundo determinados critérios.

Portanto, de acordo com a linha de raciocínio foucaultiana, o poder das normas médicas de influir sobre as açôes, isto é, de fazer com que o indivíduo se volte sobre si mesmo em observância ao imperativo de saúde, reside no processo através do qual o indivíduo é, ao mesmo tempo, objetivado pelos discursos e práticas cientificas e se subjetiva segundo os parâmetros de sua condição de objeto.

A "formação do sujeito como matriz virtual das açôes" (LEGRAND, 2007, p. 155), então, é estreitamente relacionada à abordagem do indivíduo como objeto no interior de um campo de conhecimento científico. Em outros termos, a prevalência das normas médicas sobre os comportamentos é subordinada à relação intrínseca entre subjetivação e objetivação, pois, de um lado, a experiência do indivíduo é abordada e manipulada por intervenções externas e, por outro, o indivíduo é quem se volta sobre si mesmo, de maneira a alinhar-se aos parâmetros de cuidados com saúde.

Assim, podemos citar, por exemplo, o grande sofrimento, característico dos tempos atuais, envolvido nos esforços empreendidos pelo indivíduo para eliminar o hábito de fumar. Ora, o abandono do hábito de fumar exige que o indivíduo se submeta aos exercícios de transformação de sua relação com a vida, dominada pela relação de prazer, ansiedade ou dependência biológica, em consequência da qual o cigarro adquire uma importância muito grande. Trata-se para o indivíduo de priorizar uma maneira de viver que eleja a saúde como princípio norteador de suas ações, subordinando outras motivações - o prazer de fumar, por exemplo - ao bem-estar de viver com qualidade, através de exercícios físicos, alimentação saudável, etc. O abandono do hábito de fumar impõe, portanto, que o indivíduo estabeleça novas formas de relação a si, que implicam mudanças 
de prioridades e de finalidades das experiências, que excluam o cigarro. $\mathrm{O}$ êxito do empreendimento de deixar de fumar, acarreta, por um lado, a satisfação do indivíduo consigo mesmo, a elevação de sua autoestima e, por outro, o respeito dos amigos e familiares, uma vez que demonstra o valor ético do sujeito como responsável. Dessa maneira, o sujeito se esforça para atingir a norma do "viver bem é viver com saúde", tema da campanha de prevenção contra o fumo, lançada pelo Ministério da Saúde.

A empreitada consigo mesmo contra o ato de fumar se relaciona não apenas aos discursos sobre o grau de nocividade do cigarro à saúde, mas, fundamentalmente, ao fato da norma de prevenção assumir a função de medida do valor do indivíduo responsável e autônomo. Com efeito, o que se estabelece como critério do valor pessoal de cada indivíduo, de acordo com as indicações de Ehrenberg (2000), é a autonomia como condição da qualidade de vida.

Abordaremos, inicialmente, o campo de conhecimento médico no qual se inscrevem as práticas de controle e prevenção do HIV/Aids, procurando definir os parâmetros através dos quais o indivíduo é tomado como objeto das intervenções em saúde. Daí, examinaremos a forma pela qual o indivíduo se torna sujeito de suas ações em referência a um sistema que o posiciona, tal como ressalta Golse (2001), em relação à dualidade comportamentos saudáveis/ comportamentos não saudáveis.

Como dissemos acima, essa articulação entre saberes, práticas de saúde e subjetividade é inteiramente estruturada em torno da perspectiva foucaultiana. Portanto, nossas referências bibliográficas são, fundamentalmente, de leitores e intérpretes de Foucault acerca de suas teses sobre as relaçōes entre saber, poder e sujeito. Privilegiamos, mais precisamente, os estudos de Legrand (2007) sobre o conceito de norma em Foucault, os quais nos serviram de ferramenta teórica e metodológica na formulação e análise do problema. As proposiçōes de Golse (2001) sobre as diferenças entre medicina da doença e medicina da saúde basearam nosso entendimento dos discursos e intervenções médicas sobre o HIV/Aids. O abundante material encontrado no sítio do Ministério da Saúde (Departamento Aids, DST e Hepatites Virais), tais como boletins epidemiológicos, matérias publicitárias e educativas, e pesquisa de comportamentos e atitudes, serviramnos de base de dados acerca das políticas públicas de prevenção do HIV/Aids. 


\section{População, uma realidade biológica: espaço de conhecimento e prevenção de fatores de risco}

Considerando suas especificidades conceituais, as intervenções sobre a epidemia da Aids no Brasil, de acordo com o Ministério da Saúde, podem ser diferenciadas em três fases: uma primeira, cujo alvo de intervenção médica é, fundamentalmente, o indivíduo infectado e as ações preventivas são, preponderantemente, orientados pela categoria de grupos de risco; uma segunda fase, na qual a Aids não é mais abordada como um fato restrito a determinados grupos, mas relacionada a comportamentos de risco; e uma terceira etapa, que tematiza a suscetibilidade das pessoas ao vírus, propondo o conceito de vulnerabilidade (COORDENÇÃO NACIONAL DE DST E AIDS, 1999).

A formulação dos conceitos de grupos de risco, comportamentos de risco e de vulnerabilidade está associada, conforme as indicaçôes de Golse (2001), a uma reviravolta epistemológica da Medicina. Trata-se da constituição de um novo campo teórico e prático organizado em torno de uma inquietação com a saúde. Ora, o posicionamento da saúde como alvo dos investimentos científicos, técnicos, políticos e econômicos denuncia uma ruptura com um domínio médico centrado nas investigações sobre o patológico e no tratamento do indivíduo doente. Vejamos:

Essas novas disciplinas, notadamente a medicina preditiva e a medicina de saúde pública, que escapam ao modelo curativo para visar resolutamente uma construção positiva da saúde, nos parecem o signo de uma transformação radical da medicina, mais do que um simples alargamento de seu saber devido ao puro crescimento e progresso da ciência. (GOLSE, 2001, p.273).

A anatomopatologia define, segundo Foucault (1994), a racionalidade médica propriamente moderna, fundamentando o conhecimento científico sobre o indivíduo. Esse campo médico deve ser entendido, segundo Golse (2001), com base em três paradigmas: 1) como prática e saber sobre a doença; 2) como uma explicação monoetiológica da doença; 3) como uma intervenção clínica que, orientada pelos sintomas, visa à supressão da doença e, consequentemente, ao retorno do paciente ao estado de saúde. É importante ressaltar que, nesse contexto, a saúde é definida como ausência de doença, ou seja, "a saúde é a vida no silêncio dos órgãos", tal como definiu Leriche, indicando, assim, conforme comenta Safatle (2011, p.11), que "a doença é, em última instância, o que faz o 
corpo falar [...]. [É] ela que transforma o corpo em um 'problema' que determina exigências de saber e configura necessidades de cuidado e intervenção".

Ora, é exatamente a mudança dessa concepção de saúde que está no centro dessa reorganização do campo teórico e prático da Medicina. Eis que se formula uma ideia de saúde desvinculada da noção de doença, cuja origem remete à criação da Organização Mundial de Saúde (OMS), em 1946, que, conforme o documento constitucional, surge com a missão de promover a saúde de todos os povos, entendendo-a como "[...] um estado completo de bem-estar físico, mental e social e não consistindo somente da ausência de uma doença ou enfermidade." (OMS: http://www.who.int/governance/eb/constitution/fr/index.html) Tal definição sofreu alguns reajustes, sem, contudo, alterar o essencial: a instituição da saúde como o mais importante problema médico.

Podemos assinalar aí dois desdobramentos a propósito desse novo domínio de questôes: 1) não importa qual estado, de doença ou de saúde: trata-se sempre de uma questão médica; 2) as ações médicas não se restringem aos cuidados com as dimensōes físicas e mentais dos indivíduos, mas se estendem ao campo social, uma vez que são orientadas pela problematização do bem-estar físico, psíquico e social.

Situamos, então, a questão de saber sobre esse domínio de conhecimentos e intervenções organizado em torno das preocupações com a saúde. Daí nossa primeira indagação: em que consiste o estado de saúde? Com efeito, desvinculada da noção de doença, a saúde passa a ser apreendida, de acordo com Golse (2001), como fato biológico relacionado ao processo de adaptação do organismo ao meio. Em outros termos, o estado de saúde, em vez de ser abordado como ausência de doença, quer dizer, como "silêncio dos órgãos", passa a ser avaliado em termos de potencial adaptativo do indivíduo ao seu ambiente.

A problematização da saúde referida à relação organismo/meio engendra uma nova perspectiva médica sobre a experiência do indivíduo, que engloba o biológico (condições físicas), o psíquico (comportamentos, valorização e satisfação pessoal) e o social (gerenciamento dos determinantes ambientais). Nesse contexto, a doença é abordada como um elemento variante do potencial adaptativo do indivíduo, e não mais como condicionante da falta de saúde. Portanto, as prescrições médicas, mesmo para o indivíduo portador de uma doença (indivíduos vivendo com Aids, por exemplo), são para maximizar o estado de saúde, através de boa alimentação, atividades físicas, relacionamentos 
pessoais e sociais, de acordo com as recomendações afixadas no portal sobre Aids, DST e hepatite viral do Ministério da Saúde. ${ }^{3}$ Assim, a saúde se impõe como a norma segundo a qual todos os indivíduos, doentes ou não, devem pautar os cuidados consigo mesmo, pois, como constata Bezerra (2002, p.233), "a saúde exibida como espetáculo é a prova que o sujeito dá de seu direito ao reconhecimento pessoal e social”.

Podemos, agora, passar para um segundo questionamento: como a saúde se impóe como norma de vida? Com efeito, a doença se manifesta de forma ruidosa através dos sintomas, os quais justificam e orientam a intervenção clínica. Trata-se aí, conforme as pesquisas de Foucault (1963/1994), de o clínico dirigir seu olhar treinado ao interior do corpo do sujeito padecente, buscando relacionar os sintomas às alterações morfológicas e, então, definir os procedimentos terapêuticos.

Ora, podemos dizer, em conformidade com as análises de Golse (2001), que a problematização da saúde está relacionada ao deslocamento do olhar médico sobre o corpo do doente e em direção à população, pois a tomada desta como espaço de saber e de cuidados das condiçôes de saúde dos indivíduos implica a transformação da perspectiva médica, uma vez que se trata menos de explicar e tratar o fato patológico do que de conhecer as probabilidades de ocorrência dos eventos biológicos relacionadas às condições de vida dos indivíduos para, então, intervir sobre os fatores de risco - os quais não são em si mesmos fatos patológicos, mas hábitos cotidianos, banais, modos de vida - com vistas à prevenção de doenças e à promoção de saúde.

Isso porque a população, sendo uma realidade biológica, pode ser apreendida em termos de suas regularidades, o que, em escala individual, como nos esclarece Golse (2001), não é possível, pois nesta os eventos se manifestam de maneira aleatória e imprevisível. Na população, através da estatística, pode-se conhecer os índices de nascimento, mortalidade, envelhecimento e adoecimento. Ora, é pela frequência da ocorrência dos fatos vitais que a saúde pode ser avaliada em termos de seu potencial e de seu grau de vulnerabilidade, na medida em que esses dados são esquadrinhados e relacionados aos aspectos físicos, psíquicos e ambientais da população, de tal forma que é possível estabelecer relações entre determinados fatos e certos acontecimentos biológicos.

Tal correlação fundamenta a identificação de fatores de risco, ou seja, de aspectos associados aos eventos mórbidos e aos fatores de saúde. Desse modo, os 
mais diferentes aspectos da existência humana são passíveis de serem abordados, tais como: faixa etária, sexo, escolaridade, hábitos alimentares, estilo de vida, classe social, constituição genética, acesso a saneamento, à água, clima, entre muitos outros. Assim, por exemplo, o câncer de pulmão pode ser relacionado, entre outros fatores, ao hábito de fumar, pois sua incidência é alta nos fumantes; da mesma maneira, a atividade física pode ser referida, entre outros elementos, à população longeva.

Não são os fatos concretos, como as doenças e a morte, que mobilizam as intervenções médicas, mas os fatores de risco indicadores probabilísticos da ocorrência de doenças. Com efeito, é baseando-se nos fatores de risco, como índices de enfermidade, que se definem as estratégias de prevenção de doenças, e de promoção de saúde. Nesse contexto, saúde e doença são realidades virtuais, pois são abordadas, respectivamente, como norma, em referência a qual é imperativo cuidar-se, e como perigo, contra o qual se pode lutar. Eis, então, as afirmaçôes de Golse (2001, p.281): “[...] só é risco alguma coisa que se pode quantificar, mas, paradoxalmente, não tem existência concreta [...]. Da mesma maneira, a saúde é um risco, quer dizer uma probabilidade, que depende, ela também, de um certo número de fatores [...]".

Com efeito, a intensa mobilização de políticas públicas no Brasil na luta contra o HIV traduz uma enorme preocupação com o perigo de disseminação da doença. De fato, o caráter devastador do HIV é mensurado pela sua expressão numérica, indicando não apenas que milhares de pessoas foram infectadas, mas, fundamentalmente, sinalizando a tendência crescente de incidência da infecção, principalmente - mas não somente - em categorias específicas (faixa etária, comportamento sexual, escolaridade), haja vista a presença de comportamentos sexuais considerados fatores de risco, tais como variedade de parceiros sexuais e não utilização de preservativos. $\mathrm{O}$ conhecimento de tais probabilidades orienta as tomadas de decisões e revisões dos programas de controle e prevenção. Tal prognóstico diz respeito a alguns dos aspectos apresentados nas últimas estatísticas da Aids no Brasil, presentes no site Aids/HIV. Vejamos:

O levantamento feito entre jovens, realizado com mais de 35 mil meninos de 17 a 20 anos de idade, indica que, em cinco anos, a prevalência do HIV nessa população passou de $0,09 \%$ para $0,12 \%$. O estudo também revela que quanto menor a escolaridade, maior o percentual de infectados pelo vírus da Aids (prevalência de $0,17 \%$ entre os meninos com ensino fundamental incompleto e $0,10 \%$ entre os que têm ensino 
fundamental completo). O resultado positivo para o HIV está relacionado, principal-

mente, ao número de parcerias (quanto mais parceiros, maior a vulnerabilidade), à coinfecção com outras doenças sexualmente transmissíveis e às relaçôes homossexuais. O estudo é representativo da população masculina brasileira nessa faixa etária e revela um retrato das novas infecções. ${ }^{4}$

Daí, nossa terceira questão acerca das especificidades conceituais desse campo de saúde pública: qual o estatuto médico do indivíduo em torno do qual se organizam os discursos e as práticas de prevenção e promoção de saúde? Considerando a perspectiva médica, sustentada pelos conhecimentos sobre o potencial de saúde, doenças, morte, acidentes, etc., de uma determinada população, podemos dizer que, sob essa ótica, o indivíduo adquire o estatuto de realidade biologicamente vulnerável. Ora, num domínio em que a saúde é a questão central, sendo apreendida através de cálculos dos fatores de riscos população, o indivíduo se torna objeto de uma inquirição que avalia o potencial de risco implicado em suas características, tais como: idade, constituição genética, prática alimentar, estilo de vida, uso de cigarro, uso de bebidas alcoólicas, vida sexual, etc. Portanto, é pelo seu caráter de vulnerabilidade inerente à sua condição biopsicosocial que o indivíduo se torna alvo das intervençôes médicas. Desse modo, a visada médica não só alcança todos os indivíduos, saudáveis e doentes, como também é autorizada a intervir sobre todos os aspectos de suas existências, uma vez que, mais do que abordar sintomas e patologias, trata-se, agora, de qualificar a vida, promovendo saúde e combatendo fatores de risco.

Nunca é demais assinalar que essa nova forma de abordar a situação biológica do individuo está relacionada, tal como sustenta Golse (2001), às mutações epistemológicas do campo médico. Tal reviravolta ultrapassa os limites estritamente técnico-científicos, envolvendo mudanças sociais consideráveis, uma vez que, nesse contexto, a saúde passa a ser considerada patrimônio da população, deixando de ser, portanto, uma questão do indivíduo. Nesse sentido, o cuidado com a saúde é um dever, a propósito do qual se instituem dispositivos de controle e observância de seu cumprimento. Eis aí a razão de ser da aguerrida cruzada contra o fumante, que, cada vez mais, vai sendo levado a se retirar, com seu cigarro, dos espaços de convivência social. Esse novo campo médico-político engendra novas formas de subjetivação, quer dizer, outros modos de tomar a si mesmo, de maneira a se alinhar com as exigências de cuidados com a saúde. 


\section{Vulnerabilidade e responsabilidade: processo de subjetivação}

A propósito da luta contra o HIV/Aids, os programas de controle e prevenção da doença se direcionam aos indivíduos sexualmente ativos, uma vez que o comportamento sexual pode ser um fator de risco à saúde devido à infecção pelo vírus. Portanto, é pelo caráter de vulnerabilidade, relacionado ao comportamento sexual, que os indivíduos são tomados como alvo das políticas de saúde, haja vista as campanhas extensivas à sociedade como um todo, alertando sobre o risco do sexo sem camisinha e da variedade de parceiros/as sexuais, bem como inquirindo os sujeitos sobre seus conhecimentos, atitudes e comportamentos sexuais. Tais formas de intervenção conduzem ao engajamento do sujeito na luta contra a epidemia, incitando-o a reconhecer sua função de agente de saúde, atuando sobre seus hábitos e práticas cotidianas, regulando-os segundo a norma da qualidade de vida.

Ora, a responsabilidade caracteriza a forma de implicação do sujeito no processo de normalização da conduta na luta contra o HIV/Aids. Não é por acaso que a responsabilidade é tema frequente nas investigações sobre as estratégias de prevenção do HIV/Aids. Isso pode ser visto em Fernandes (1994), que, por exemplo, estuda as práticas educativas, tendo em vista o reconhecimento do estatuto de responsabilidade do cidadão; também em Regato e Essmar (2004), que investigam portadores e profissionais acerca da atribuição de responsabilidade sobre a infecção, entre outros. Como afirma Bezerra (2002, p. 233), "propaga-se a crença de que o indivíduo pode e deve ser capaz não só de evitar doenças, mas, sobretudo, de gerenciar os riscos à sua saúde, minimizando de forma consciente a possibilidade de patologias e otimizando seus próprios recursos". Portanto, é como sujeito responsável que o indivíduo mantém uma vigilância rigorosa sobre seus hábitos sexuais, impondo-se o imperativo da prevenção, de nunca transar sem camisinha.

Com efeito, a problematização dos comportamentos de risco relacionados à transmissão do HIV responsabiliza o sujeito sobre seu estado de saúde, incitando-o a uma reorientação dos hábitos sexuais. Assim, é a propósito do estado de vulnerabilidade que o sujeito inscreve a norma de saúde em seu comportamento sexual, impondo-se a observância das normas de prevenção, atuando, assim, 
como sujeito responsável. Trata-se, para o sujeito, de imprimir em suas ações e

atitudes sexuais os limites da prevenção dos fatores de riscos, subvertendo, então, as expectativas sexuais, subordinando os anseios de satisfação amorosa e/ou pulsional, que marcaram as experiências sexuais na cultura ocidental moderna, conforme indicações de Giddens (1992), às obrigações com a saúde.

Assim, é possível dizer que um traço importante das estratégias para influenciar mudanças de atitudes sexuais é o de associar o desempenho da responsabilidade do sujeito sobre seus atos sexuais ao desenvolvimento cognitivo. Com isso, os dispositivos de saúde acarretam a mudança da dimensão do sujeito, redefinindo sua atitude em relação à sua vida sexual. Trata-se de descentralizar as temáticas das pulsões e do desejo, que foram alavancadas, conforme as pesquisas de Foucault (1974-1975/1999), pela prática da confissão no interior do ritual católico da penitência das faltas, e dominaram a abordagem científica no século XIX e em meados do XX, da relação entre subjetividade e sexualidade, situando a atividade racional no centro da questão da atuação responsável do sujeito sobre seus atos sexuais. Daí as afirmaçôes de Amorim e Szapiro (2008, p. 648-649): “apoiandose nesta concepção iluminista do sujeito da razão, a lógica da prevenção levará a atribuição de responsabilidade a cada um pelas decisões que toma e, obviamente, pelas escolhas sobre os riscos que pode correr".

Todos os sujeitos sexualmente ativos, independente das diferenças e diversidades que tal função envolve, tais como mulheres, homens, travestis, heterossexuais, homossexuais, bissexuais, monogâmicos ou poligâmicos, devem assumir os encargos de conduzir uma vida sexual sem riscos. Levando em consideração o ponto de vista epistemológico, podemos asseverar que os discursos preventivos desassociam a observância da norma de saúde das tendências sexuais dos sujeitos. Destarte, vemos nos programas de educação e saúde a tematização da diversidade sexual sob o prisma de uma perspectiva desmoralizante e preventiva da sexualidade, como a discussão sobre a homossexualidade como matéria central da historia em quadrinhos "Perguntas e Repostas", publicada pelos Ministério da Educação e da Saúde, a propósito do Projeto Saúde e Prevenção nas Escolas (2003). Portanto, é no que se refere à prevalência da razão, quer dizer, ao desprendimento das amarras afetivas, ou melhor, à assunção da posição de autonomia, que o sujeito responsável se empenha na tarefa de se sobrepujar ao indivíduo vulnerável. Eis aí a incumbência de um projeto civilizatório: o controle dos fatores de risco. 
Para concluir, podemos dizer que essa empreitada emancipatória dos fatores de risco reconfigura, no jogo social, as polaridades entre o normal/anormal a partir da oposição entre comportamentos saudáveis/comportamentos de risco, a partir dos quais os sujeitos serão admirados/discriminados, aceitos/rejeitados, vítimas de preconceitos, sofrerão com baixa autoestima, depressões, sentimentos de insuficiências, etc. ${ }^{5}$

\section{Referências}

ALENCAR, T.M.D.; NEMES, M.I.B.; VELLOSO, M.A. Transformaçôes da "Aids aguda" para a "Aids crônica": percepção corporal e intervenções cirúrgicas entre pessoas vivendo com HIV e Aids. Ciência \& Saúde Coletiva, v.13, n.6, nov./dez., 2008.

ALMEIDA, M.R.C.B.; LABRONICI, L.M. A trajetória silenciosa de pessoas portadoras do HIV contada pela história oral. Ciência \& Saúde Coletiva, v.12, n.1, p.263-274, 2007.

BEZERRA, B.J. O ocaso da interioridade e suas repercussōes sobre a clínica. In: PLASTINO, C.A. (Org.). Transgressôes. Rio de Janeiro: Contracapa, 2002. p.229-239.

BRASIL. Ministério da Saúde. Coordenação Nacional de DST e Aids. Política Nacional de DST/Aids: princípios e diretrizes. 1 ed. Brasília: Ministério da Saúde, 1999.

. Ministério da Saúde. Departamento de DST, Aids e Hepatites Virais. Histórias

em quadrinhos HQ-SPE. Disponível em: <www.aids.gov.br/publicacao/historias-emquadrinhos-hq-spe>. Acesso em: 28 jun 2012.

. Ministério da Saúde. Departamento de DST, Aids e Hepatites Virais: www.aids. gov.br. Previna-se. Disponível em: <http://www.aids.gov.br/pagina/previnase>. Acesso em: 28 jun 2012.

. Ministério da Saúde. Departamento de DST, Aids e Hepatites Virais: www.aids. gov.br. Boletim epidemiológico Aids. Brasília-DF, Ano VIII, n. 1, Jun./Dez. 2010; Jan./ Jun. 2011. Estatísticas da Aids no Brasil. Disponível em: < http://www.aidshiv.com.br/ estatisticas/>. Acesso em: 28 jun 2012.

EHRENBERG, A. La Fatigue d'être soi: dépression et société. Paris: Odile Jacob, 2000.

FERNANDES, J.C.L. Práticas educativas para prevenção do HIV/Aids: aspectos conceituais. Caderno de Saúde Pública. Rio de Janeiro, v.10, n.2, p.171-180, abr/jun, 1994. FOUCAULT, M. A história da sexualidade II - o uso dos prazeres. 7 ed. Rio de Janeiro: Graal, 1994.

. A propôs de la généalogie de l'étique: un aperçu du travais en cours. In: DREYFUS, H.; RABINOW, J. Michel Foucault un parcours philosophique. Paris: Gallimard, 1984. 

. Nascimento da Clínica. 4. ed. Rio de Janeiro: Forense Universitária, 1994.

GIDDENS, A. Sexualidade, amor e erotismo nas sociedades modernas. São Paulo: UNESP, 1992. GOLSE, A. De la Médecine de la maladie a la Médecine de la santé. In: ARTIÈRES, P.; SILVA, E. Michel Foucault et la medicine: lectures et usages. Paris: Kimé, 2001.

LEGRAND, S. Les normes chez Foucault. Paris: PUF, 2007.

ORGANISATION MONDIALE DE LA SANTE. Constitution de l'Organisation mondiale de la Santé. Disponível em: http://www.who.int/governance/eb/constitution/fr/ index.html. Acesso em: 28 jun 2012

REGATO, V.C.; ASSMAR, E.M.L. A Aids de nossos dias: quem é o responsável? Estudos de Psicologia, v.9, n.1, p.1671-1677, 2004.

SAFATLE, V. O que é uma normatividade vital? Saúde e doença a partir de Georges Canguilhem. Sci. Stud, v.9, n.1, p.11-27, 2011.

\section{Notas}

${ }^{1}$ Disponível em <www.aids.gov.br/pagina/previnase>. Acesso em: 28 jun 2012.

${ }^{2}$ Disponível em: <www.aids.gov.br/publicacao/historias-em-quadrinhos-hq-spe>. Acesso em: 28 jun 2012.

${ }^{3}$ Disponível em: <http//www.aids.gov.br>. Acesso em: 28 jun 2012.

${ }^{4}$ Disponível em: <http://www.aidshiv.com.br/estatisticas/>. Acesso em: 28 jun 2012.

${ }^{5}$ C.V.Q. Pinheiro definiu, estruturou e redigiu o texto, com exceção de alguns parágrafos sobre dados de HIV/Aids; N. Medeiros pesquisou o HIV/Aids, redigiu e realizou pesquisa bibliográfica. 


\section{Prevention Practices of HIV / AIDS and Process of Subjectivation}

Since public policies for prevention and control of HIV/ Aids address the individuals' sexual activity in order to prevent risky sexual behavior, one can infer the normative character of such interventions, as they assess the subject's conduct using health criteria, which are imposed as a measure for sexual experience. As such, one can also assume that strategies based on preventive codes to regulate sexual behavior involve a process of subjectivation. This contention is based on the Foucauldian conceptions of moral experience, which he divides into three aspects: the rule, the actions, and the relationship with oneself. The sexual behavior was made object of preventive measures against HIV/Aids based on a medical knowledge field which approaches health from the relationship between organism and environment, including all the biopsychosocial aspects. Accordingly, individuals are taken as targets of health policies because of the vulnerability that is ascribed to sexual behavior. It is thus a question of investigating the risk factors related to the occurrence of the syndrome among the population. Hence, it is due to the underlying statute of vulnerability attributed to the expression of sexuality that individuals internalize the health guidance, applying it to their relationship with themselves, and impose on themselves a healthy sexual behavior. So, this paper investigates the prevalence of medical guidance in subjects' sexual attitudes, based on the intrinsic relations between the way the individual is addressed by medical knowledge and the process by which individuals direct their actions in order to obey health guidance.

> Key words: obesity; practice of prevention of HIV/Aids; norms; process of subjectivation; Michel Foucault. 